\title{
O ESTRANHO E A METAMORFOSE EM DUAS NARRATIVAS CONTEMPORÂNEAS: REFLEXÕES SOBRE O ESPAÇO
}

\author{
Orivaldo Rocha da Silva \\ Mestre em Letras pela Universidade de São Paulo (USP) \\ Doutorando em Letras pela Universidade Presbiteriana Mackenzie (UPM) \\ orocha@uol.com.br
}

\section{RESUMO}

O objetivo deste trabalho é propor algumas reflexões acerca do espaço literário, tomando por base dois exemplos de narrativas contemporâneas - uma brasileira, de Duílio Gomes ("O ovo com solenidade") e uma portuguesa, de Teolinda Gersão (“Um casaco de raposa vermelha") - filiadas, em tese, ao grande gênero que poderíamos identificar como fantástico. Esclareça-se, no entanto, que os dois contos não pertencem, a rigor, ao gênero citado, aproximando-se muito mais do chamado fantástico modal.

Palavras-chave: estranho, metamorfose, fantástico.
This work aims proposing some reflections about the literary space, based on two examples of contemporary narratives $-\mathrm{a}$ Brazilian one, by Duílio Gomes ("O ovo com solenidade") and a Portuguese one, by Teolinda Gersão ("Um casaco de raposa vermelha") - affiliated, in theory, with the great genre that we could identify as fantastic. It should be noted, however, that the two tales do not belong strictly to the genre quoted, approaching much more of the fantastic as a mode.

Keywords: strange, metamorphosis, fantastic.

\section{ABSTRACT}

Antes de tudo, partimos do princípio de que o espaço ficcional pode e deve ser analisado no âmbito dos estudos literários como um elemento que interage ativamente com as demais categorias clássicas - tais como a personagem, o narrador, o foco narrativo, com eles significando, ressignificando e iluminando aspectos que podem vir a conduzir a uma apreensão efetiva dos sentidos mais profundos de um texto literário. Partindo desta premissa, afastamos por completo a interpretação do espaço literário como mero pano de fundo, como mero espaço geográfico no qual as personagens são dispostas. 
Em ensaio que é parte integrante de obra dedicada a análises que tematizam o espaço na literatura, Barbieri (2009) considera que

A construção espacial da narrativa deixa de ser passiva - enquanto um elemento necessário apenas à contextualização e pano de fundo para os acontecimentos - e passa a ser um agente ativo: o espaço, o lugar como articulador da história. A percepção deste pela personagem e seu percurso dão ao leitor uma maior compreensão da constituição de ambos e ampliam as possibilidades de significação do texto. (BARBIERI, 2009, p. 105)

O espaço literário, dessa forma, assumindo a posição de "articulador da história", não mais pode ser encarado como um elemento decorativo no texto, muito pelo contrário, uma vez que pode vir a ser o responsável pela ampliação dos sentidos de um texto, sempre considerando sua atuação em conjunto e em estreita relação com os demais elementos constituintes da arquitetura literária.

Ainda a reforçar essas considerações iniciais no que se refere ao espaço no texto literário, temos a constatação de Aguiar (2017, p. 23) de que "o espaço fascinou filósofos, cientistas, políticos, mas também escritores e artistas em geral", ou seja, é possível avaliar que a questão do espaço sempre esteve no horizonte próximo das especulações em diversas áreas e, mais especificamente no campo literário, que é o nosso foco, a questão da espacialidade percorre os mais diversos gêneros e deve ser analisada com profundidade:

Da ficção científica aos contos de Clarice Lispector, discutir literatura implica pensar o quanto o espaço é uma peça fundamental para o processo de construção poética. No entanto, se compararmos com os estudos dedicados a outros aspectos da narrativa, tais como a personagem ou o foco narrativo, veremos o quanto apenas em tempos recentes o espaço tem recebido um tratamento mais aprofundado. (AGUIAR, 2017, p. 23) 
Reconhecida, então, a sua centralidade nos estudos literários, reitera-se que os estudos acerca do elemento espaço apenas bem recentemente experimentaram certo desenvolvimento no que diz respeito às investigações e pesquisas acadêmicas.

O objetivo principal deste estudo é o de propor algumas reflexões acerca do espaço literário, tomando por base dois exemplos de narrativas contemporâneas - uma brasileira e uma portuguesa - filiadas, em tese, a um grande gênero que poderíamos identificar como fantástico, na esteira da conceituação proposta por Todorov e que associa a ele, sobretudo, a hesitação do leitor diante de uma situação narrada. A partir dessa hesitação, a existência do gênero denominado fantástico se confirmaria ou não, considerando a decisão do leitor. Ou nos termos do teórico búlgaro:

o fantástico [...] dura apenas o tempo de uma hesitação: hesitação comum ao leitor e à personagem, que devem decidir se o que percebem depende ou não da "realidade", tal qual existe na opinião comum. No fim da história, o leitor, quando não a personagem, toma contudo uma decisão, opta por uma ou outra solução, saindo desse modo do fantástico. Se ele decide que as leis da realidade permanecem intactas e permitem explicar os fenômenos descritos, dizemos que a obra se liga a um outro gênero: o estranho. Se, ao contrário, decide que se devem admitir novas leis da natureza, pelas quais o fenômeno pode ser explicado, entramos no gênero do maravilhoso. (TODOROV, 2003, p. 47-48)

Esclareça-se, no entanto, que os dois contos a serem analisados parecem não pertencer, a rigor, ao fantástico considerado como gênero, alinhando-se, muito mais, a um entendimento deles como associados ao fantástico enquanto modo. A questão da delimitação teórica precisa do fantástico tem sido objeto de discussões recorrentes a partir dos estudos balizadores de Todorov que tiveram como principal mérito a tarefa de organizar os conhecimentos disponíveis até então. Uma das produções teóricas que se prestaram a 
enriquecer esse debate (GAMA-KHALIL, 2013) propõe, desde as suas primeiras linhas, problematizar as dificuldades de nomear as narrativas fantásticas:

A construção da narrativa fantástica pode assumir variadas formas, agregar diversificados elementos e, dependendo da maneira como é tecida a sua trama, os estudiosos delegam a ela variáveis denominações. Assim, uma grande dificuldade é a nomeação da literatura que faz brotar em seu enredo o insólito. Alguns estudos tentam organizar as diversas formas da narrativa fantástica e agrupá-las em "gêneros". Nesse caso, dando ênfase às diferenças, demarcam territórios em que o fantástico ficará situado ao lado de gêneros vizinhos. Em outra linha de entendimento, teóricos procuram compreender essa literatura por uma visão que privilegia não somente a diferença, mas as similitudes e, nesse sentido, adotam a perspectiva do "modo". (GAMA-KHALIL, 2013, p. 19)

Em linha, pois, com o que se observa nas explicitações da ensaísta mais acima citada, entendemos que as duas narrativas contemporâneas em tela podem ser reconhecidas como representantes do chamado fantástico modal, uma vez que o fantástico enquanto gênero, sempre com base nos conceitos de Todorov, está fortemente atrelado a um determinado período histórico (séculos XVIII e XIX) e traz para o primeiro plano a questão das diferenças, não a dos pontos em comum.

O meu enfoque sobre a literatura fantástica dirige-se não no sentido de entendê-la a partir da noção de gênero, enquadrando-a em um período histórico preciso. Por esse motivo, acredito ser mais viável considerar a literatura fantástica como um "modo". Caso se parta de um mirante que considera seu enquadramento por intermédio do gênero, reduzimos o ponto de alcance de uma vasta literatura que fratura a realidade e se ergue como uma estética em que a incerteza é a base de criação, literatura essa que existe desde os primórdios, fruto do imaginário dos seres humanos. Pela vertente que considera o fantástico como um modo, podemos alargar o enfoque analítico sobre essa literatura, porque o que mais nos interessa nas pesquisas sobre a literatura fantástica não é datar determinada forma de fantástico nem enfeixá-la em uma espécie ou outra, mas compreender de que 
maneira o fantástico se constrói na narrativa e, o mais importante, que efeitos essa construção desencadeia. (GAMA-KHALIL, 2013, p. 30)

Muito mais do que apenas rotular as histórias como fantásticas ou não, nosso interesse reside na discussão de elementos utilizados pelos autores e que colocam, em primeiro plano, a espacialidade como absolutamente fundamental para um trabalho de criação literária que permite a instauração, por exemplo, dos aspectos do estranho ou insólito (na narrativa brasileira) e da metamorfose (na narrativa portuguesa). Note-se, todavia, que não é objeto central de discussão neste texto as questões classificatórias ligadas ao fantástico, seja enquanto gênero, seja enquanto modo. Dessa forma, limitemos o entendimento dos aspectos do estranho/insólito e da metamorfose como possíveis produtos resultantes de um trabalho criativo que, em nossa avaliação, privilegia e nos permite, ainda que brevemente, discutir a espacialidade.

Observemos então, inicialmente, que em ambas as produções selecionadas para análise, a questão do limiar, da fronteira se mostrará como central e, em última instância, como o elemento que desencadeia todos os acontecimentos observados no desenrolar das histórias.

Neste ponto, tratemos, ainda que sumariamente, dos autores eleitos e suas narrativas, iniciando com o brasileiro Duílio Gomes (1944-2011) e o conto "O ovo com solenidade", parte integrante da coletânea Os Melhores Contos Fantásticos, de 2006.

O mineiro Duílio Gomes tem sua trajetória de escritor atrelada ao Suplemento Literário, publicação criada em 1966 pelo também contista Murilo Rubião e vinculada ao Diário Oficial de Minas Gerais. Em 1982, Duílio assumiu a secretaria do suplemento, a 
convite de Rubião. A partir de 1994, a publicação foi transferida para a Secretaria de Estado da Cultura e passou a se chamar Suplemento Literário de Minas Gerais, com periodicidade bimensal, circulando aos sábados. Em agosto de 2016, portanto, o SLMG comemorou 50 anos de existência - 1.300 edições lançadas no período. Alguns nomes que surgiram no suplemento e que alcançaram projeção nacional, além do próprio Murilo Rubião e Duílio Gomes: Sérgio Sant'Anna, Humberto Werneck e Luiz Vilela. A obra de Duílio Gomes foi traduzida para oito línguas e seus contos já foram incluídos em pelo menos 33 antologias e coletâneas de contos curtos.

$\mathrm{O}$ argumento de "O ovo com solenidade" pode ser resumido por meio de seus segmentos iniciais:

O cego estava quebrando o ovo para fazer uma omelete quando o porco entrou na cozinha. Sentiu-o aos seus pés; em silêncio, cheirava os seus pés. O cego estava de sandálias e a saliva do porco era uma coisa quente e líquida molhando o seu calcanhar direito. Os músculos do cego se retesaram. Sua mulher e sua filha haviam saído. Elas sabiam do grande medo que ele tinha de porcos e por isso os trancavam no chiqueiro. O cego percebeu, dentro da névoa do seu medo, que eles haviam arrebentado as tábuas podres do chiqueiro e saído. (GOMES, 2006, p. 693)

Toda a ação do conto acontece na cozinha. Um segundo espaço - o chiqueiro -, onde os porcos ficavam trancados, também é citado. O chiqueiro teve suas portas arrebentadas e os porcos se dirigiram à cozinha, que já contava, tão logo tem início a narrativa, com a presença do cego.

O aspecto mais evidente a ser destacado no que diz respeito à temática do espaço no conto em tela é o da questão da fronteira, do limiar, uma vez que, ao arrebentar as portas do chiqueiro e acessar a cozinha, os porcos transpõem o espaço permitido (chiqueiro) e 
acessam o espaço interdito (cozinha). E a passagem de um espaço a outro se dá através de uma escada: “As tábuas da escada que dava do quintal para a cozinha rangeram. 'Estão subindo os outros', pensou o cego e o seu terror foi tão intenso que ele sentiu, no escuro poço de sua vertigem, as pernas bambearem." (GOMES, 2006, p.694).

De início, a atmosfera do estranho é construída pela reunião de elementos do cotidiano, do real, do banal: o que haveria de especial em um cego que cria porcos e está a preparar uma omelete na cozinha de sua casa? Afinal, o que haveria de inusitado até se, na cozinha desse cego, por um descuido qualquer, seus porcos adentrassem o ambiente? $\mathrm{Na}$ estrutura narrativa do conto, no entanto, a categoria do espaço parece desempenhar uma função destacada na sua composição ao inserir, no aparente prosaico absoluto preliminar do conto, determinados índices que podem ser fortemente identificados como atuantes num trabalho de criação de uma atmosfera associada intimamente ao estranho, ao insólito. Senão, vejamos: "os velhos e agudos dentes do porco"; "o cheiro enjoativo do ovo sobre o prato"; "superfície úmida da pia"; "objeto morno e redondo"; "o ruído dos porcos mastigando"; "a bolha de saliva arrebentando". É importante destacar também que tais índices que auxiliam na composição de uma "atmosfera do estranho" na narrativa estão invariavelmente dispostos num campo semântico negativo e associados à percepção, à sensação que provocam nos outros sentidos do cego. E é isso que, de certa forma, será explicitado por um dos pioneiros dos estudos acerca do espaço no Brasil:

Não deve o estudioso do espaço, na obra de ficção, ater-se apenas à sua visualidade, mas observar em que proporção os demais sentidos interferem. Quaisquer que sejam os seus limites, um lugar tende a adquirir em nosso espírito mais corpo na medida em que evoca sensações. (LINS, 1976, p. 92) 
Por fim, é importante lembrar que o cego, privado do sentido da visão, talvez o mais importante dos sentidos, já no fechamento da narrativa, compreende que os porcos não estavam ainda com sua fome saciada.

Recordemos aqui que, em determinado momento da história, o cego, buscando fazer com que os porcos esquecessem suas pernas, passa a lançar ao chão toda sorte de alimentos que percebera à sua frente, na pia. E é digno de nota que o narrador destaque que a leitura definitiva da situação é realizada "com a profunda e mágica percepção dos cegos" (GOMES, 2006, p. 695). O estranho, o insólito... e uma espécie de sexto sentido do cego?

Falemos agora de Teolinda Gersão (1940), escritora portuguesa contemporânea já com uma longa e premiada carreira de 36 anos. Desde o primeiro romance - O Silêncio (1981) -, a escritora teve o seu talento reconhecido, sendo agraciada, nesse ano e também em 1989, com o Prêmio de Ficção do Pen Clube. Surgindo para as letras na esteira da geração de grandes prosadores concebidos no período pós-Revolução dos Cravos (1974), Teolinda, desde o início, evidenciou um trabalho literário que permitia ao analista mais atento identificar um projeto de escrita, já que a autora trabalhava, desde o romance de estreia, com certos temas que serão revisitados, de uma forma ou de outra, em sua produção posterior: a casa, a mulher e a linguagem (a escrita).

Com apenas uma obra lançada no Brasil - A árvore das palavras foi publicada aqui em 2004, embora a edição portuguesa seja de 1997 -, a autora, recentemente (setembro de 2017), esteve em várias capitais brasileiras divulgando o lançamento de A cidade de Ulisses, originalmente publicado em Portugal no ano de 2011. A expectativa, a partir de agora, é que outras obras suas possam se tornar mais acessíveis ao leitor brasileiro. 
A narrativa eleita para este trabalho é "Um casaco de raposa vermelha", parte integrante da obra $A$ mulher que prendeu a chuva e outras histórias, de 2007 . Trata-se da terceira incursão da autora ao gênero conto. Seu argumento pode ser vislumbrado pela reprodução dos fragmentos a seguir:

Ao voltar um dia para casa, uma pequena empregada bancária vê numa loja de peles um casaco de raposa vermelha. Pára diante da vitrine, com um calafrio de prazer e de desejo. Porque aquele é o casaco que sempre desejou ter na vida. [...] Aquele é uma peça rara, única, jamais vira um tom assim, fulvo, mesclado, com reflexos de cobre e brilhante como se estivesse a arder. (GERSÃO, 2007, p. 117)

De modo distinto ao que se observou no conto de Duílio Gomes, a ação na história de Teolinda Gersão desenvolve-se em mais de um espaço, embora fique novamente evidenciada, desde o início - e é esse o ponto mais notável a aproximá-la da narrativa anterior - a presença da fronteira, do limiar representado agora pela vitrine da loja de peles, o elemento desencadeador dos acontecimentos.

A narrativa de Teolinda introduz um "objeto do desejo" que está postado além do limiar representado pela vitrine: um casaco de raposa vermelha. E será justamente esse objeto (mágico?) o responsável pelo efeito de metamorfose que parece ter sido provocado na moça depois de ela ter primeiro avistado a peça e após ter experimentado o casaco.

Seria admirada, também ela, seguida com os olhos quando passasse - mas não era isso que a fazia sorrir secretamente, era antes uma satisfação interior, uma certeza obscura, uma sensação de harmonia consigo própria, que extravasava em pequenos nadas, deu conta. Como se o ritmo da respiração mudasse, fosse mais repousado e mais profundo. [...] As pernas ágeis, os pés ligeiros. Toda ela mais leve, rápida, com movimentos fáceis do dorso, dos ombros, dos membros. (GERSÃO, 2007, p. 119) 
Os primeiros sinais de transformação da empregada bancária, ainda que explicitados de modo pouco evidente, são inicialmente postos em xeque, numa tentativa de racionalizar o acontecimento: “É por causa da ginástica, pensou, por alguma razão começara a fazer regularmente exercício. Havia meses já que conseguia correr duas horas por semana no campo de treino." (GERSÃO, 2007, p. 119).

Ocorre que os efeitos da metamorfose se acentuam, e os índices dessa transformação alteram e apuram significativamente todos os sentidos da moça, evidenciando o surgimento de uma identidade animal em lugar de uma identidade humana. E isso é perceptível, por exemplo, pela presença dos seguintes fragmentos:

A sua capacidade de percepção crescia, notou, mesmo à distância ouvia ruídos diminutos, que antes passariam despercebidos, [...]

[...] pressentia também, muito antes de elas terem lugar, as mudanças atmosféricas, o virar do vento, o subir da humidade [...]

E os cheiros, um mundo de cheiros, sentiu, como uma dimensão ignorada das coisas a que agora se tornara sensível, [...]

Interessava-se de repente por animais, [...] e uma palavra the ficava por vezes boiando insistentemente na memória: predador.

Tinha mais fome, agora, sentiu arrumando os livros e abrindo a porta da cozinha, $[\ldots]$

(GERSÃO, 2007, p. 119-120)

É oportuno destacar, neste ponto, que os processos de metamorfose não constituem, em absoluto, uma novidade na literatura. Nos termos de Modesto Carone (1996) dissertando a respeito da novela $A$ metamorfose, de Kafka, 
[...] os mitos clássicos e as fábulas, as narrativas dos povos primitivos e os contos de fadas são ricos em acontecimentos como este [metamorfose]. Mas nenhum leitor esclarecido fica perturbado com eles, não só porque essas metamorfoses em geral são reversíveis, mas também porque podem ser logo percebidas como manifestações de um estágio de consciência ingênuo, pré-científico, que exime o leitor de julgá-los segundo os padrões de sua própria experiência. (CARONE, 1996, p. 22)

No entanto, em Kafka e em Teolinda, o processo de metamorfose é de outra ordem. $\mathrm{E}$ seus efeitos junto ao leitor, igualmente de outra ordem.

Fechando estas breves considerações acerca da temática do espaço em contos contemporâneos, vale destacar também que, na narrativa de Teolinda Gersão, conforme pontua Clara Rocha em ensaio dedicado ao conto em tela, teríamos "[...] o lugar onde a própria escrita se metamorfoseia e se dá a ver como work in progress, na medida em que passa por uma recontextualização" (ROCHA, 2012).

Está a autora a lembrar que a narrativa do "casaco" já fora reproduzida como um dos fragmentos do pseudodiário Os guarda-chuvas cintilantes (1984), também de Teolinda Gersão. Nele, no entanto, não havia o título adotado "Um casaco de raposa vermelha" e era dada a referência "É uma história curiosa, acontecida num país nórdico, que leio num jornal: [...]" (GERSÃO, 1984, p. 74). E como bem observa a ensaísta, essa alteração promovida na versão publicada em 2007 "modifica por completo o protocolo de leitura proposto pela primeira versão" (ROCHA, 2012). Metamorfoses: na história e na escrita.

\section{REFERÊNCIAS}


AGUIAR, Cristhiano. Narrativas e espaços ficcionais: uma introdução. São Paulo: Editora Mackenzie, 2017.

BARBIERI, Claudia. "Arquitetura literária: sobre a composição do espaço narrativo". In: BORGES FILHO, Oziris; BARBOSA, Sidney (orgs.). Poéticas do espaço literário. São Carlos: Claraluz Editora, 2009. p. 105-126.

BORGES FILHO, Oziris. "Espaço, percepção e literatura". In: BORGES FILHO, Oziris; BARBOSA, Sidney (orgs.). Poéticas do espaço literário. São Carlos: Claraluz Editora, 2009. p. 167-189.

CARONE, Modesto. "O parasita da família". Conferência pronunciada na Sociedade Brasileira de Psicanálise de São Paulo, em 1983, por ocasião do centenário de nascimento de Franz Kafka. In: RÖHL, Ruth (org.). A expressão da modernidade no século XX. São Paulo: FFLCHUSP, 1996. p. 21-30.

GAMA-KHALIL, Marisa Martins. "O espaço e as configurações da narrativa fantástica: Uma leitura de A invenção de Morel”. Disponível em:

$<$ http://www.abralic.org.br/anais/cong2008/AnaisOnline/simposios/067.htm>. Acesso em: 23 jul. 2018.

"A Literatura fantástica: gênero ou modo?". Terra roxa e outras terras: Revista de Estudos Literários, v. 26 (dez 2013), p. 18-31. Disponível em:

$<$ http://www.uel.br/revistas/uel/index.php/terraroxa/article/view/25158>. Acesso em: 25 jul. 2018.

GERSÃO, Teolinda. Os guarda-chuvas cintilantes. Lisboa: O Jornal, 1984. p. 74-79.

"Um casaco de raposa vermelha". A mulher que prendeu a chuva e outras histórias.

Lisboa: Sudoeste Editora, 2007. p. 117-123.

GOMES, Duílio. "O ovo com solenidade". In: COSTA, Flávio Moreira da (org.). Os melhores contos fantásticos. Rio de Janeiro: Editora Nova Fronteira, 2006. p. 693-695.

LINS, Osman. Lima Barreto e o espaço romanesco. São Paulo: Ática, 1976.

ROCHA, Clara. "Para uma leitura de 'Um casaco de raposa vermelha', de Teolinda Gersão". Revista Diacrítica, v. 26, n. 3. Braga: 2012. Disponível em:

<http://www.scielo.mec.pt/scielo.php?script=sci_arttext\&pid=S0807-89672012000300009>. Acesso em: 7 dez. 2017.

TODOROV, Tzvetan. Introdução à Literatura Fantástica. Trad. Maria Clara Correa Castello. 2. ed. São Paulo: Perspectiva, 2003.

Artigo recebido em: 31 de maio de 2018. Artigo aprovado em: 18 de julho de 2018. 